\title{
Verzeichnis der verwendeten Siglen und Abkürzungen
}

\begin{tabular}{|c|c|}
\hline * & $\begin{array}{l}\text { vor der Laufnummer der Urkunde markiert ein Deperditum (verlo- } \\
\text { rene Urkunde) in DD Jerus. }\end{array}$ \\
\hline$\dagger$ & $\begin{array}{l}\text { vor der Urkundennummer markiert ein Spurium (mittelalterliche } \\
\text { oder moderne Fälschung) in DD Jerus. }\end{array}$ \\
\hline Anm. & Anmerkung(en) \\
\hline App. & Appendix \\
\hline $\mathrm{Bd}(\mathrm{e})$. & Band (Bände) \\
\hline CDB & Codex diplomaticus et epistolaris Regni Bohemiae \\
\hline CCCM & Corpus Christianorum Continuatio Mediaevalis \\
\hline $\mathrm{CGOH}$ & $\begin{array}{l}\text { Cartulaire général de l’Ordre des Hospitaliers de S. Jean de Jérusa- } \\
\text { lem }\end{array}$ \\
\hline DA & Deutsches Archiv für Erforschung des Mittelalters \\
\hline Ders. & derselbe \\
\hline Dies. & dieselbe \\
\hline Diss. & Dissertation \\
\hline ebd. & ebenda \\
\hline EMA & $\begin{array}{l}\text { Europa im Mittelalter. Abhandlungen und Beiträge zur historischen } \\
\text { Komparatistik }\end{array}$ \\
\hline FSI & Fonti per la Storia d’Italia \\
\hline Hg.; hg. & Herausgeber, herausgegeben \\
\hline insb. & insbesondere \\
\hline Kap. & Kapitel \\
\hline loc. cit. & loco citato \\
\hline $\mathrm{MGH}$ & Monumenta Germaniae Historica \\
\hline LdL & Libelli de lite imperatorum et pontificium \\
\hline SS & Scriptores \\
\hline SS. rer. Germ. & $\begin{array}{l}\text { Scriptores rerum Germanicarum in usum scholarum separatim } \\
\text { editi }\end{array}$ \\
\hline $\mathrm{n}^{\circ}$ & Nummer \\
\hline op. cit. & opere citato \\
\hline PL & Patrologia Latina \\
\hline $\mathrm{RHC}$ & Recueil des historiens des croisades \\
\hline Arm. & Documents arméniens \\
\hline Grecs & Historiens grecs \\
\hline Hoc. & Historiens occidentaux \\
\hline Hor. & Historiens orientaux \\
\hline RHGF & Recueil des Historiens des Gaules et de la France \\
\hline ROL & Revue de l’Orient Latin \\
\hline Rolls Series & Rerum Britannicarum medii ævi scriptores \\
\hline $\mathrm{RRH}$ & Regesta regni Hierosolymitani \\
\hline s. & siehe \\
\hline scil. & scilicet \\
\hline u. & und \\
\hline
\end{tabular}


u. a. übers.

v. VCSS

vgl.

wdh. unter anderem/anderen, und andere übersetzt

von

Variorum Collected Studies Series

vergleiche

wiederholt 